\title{
COLOMBIA, EDUCACIÓN INEXORABLE
}

\author{
Julián Andrés Alarcón González \\ Universidad Pedagógica y Tecnológica de Colombia \\ julian.alarcon03@uptc.edu.co
}

Received: March 20, 2021

Accepted: April 5, 2021

\section{How to cite this article (APA, 7th ed.):}

Alarcón, J. A. (2021). Colombia, Educación inexorable. ENLETAWA Journal, 14(1), 133-135.

Colombia, un país donde ser maestro, docente o profesor, o en otras palabras un representante del crecimiento básico e íntegro de muchos niños del país, no es valorado. Este ensayo tratará de aquella educación nula, una transmisión de conocimientos sin esfuerzo, un gobierno que desacredita una labor fundamental como lo es ser maestro y lo que conlleva la falta de profesionalismo.

Primero que todo, pongamos la mirada en la caldera del país, el gobierno, en el que cientos de maestros son poco valorados, ya sea sin apreciar sus esfuerzos o el bajo salario que, ante un trabajo y una profesión tan primordial que manejan estos padres de la educación no es lo merecido, pero ¿ahora sabemos la causa de la protesta contra el estado? Con gran razón, por lo que pensamos ¿Cómo es posible que un congresista que únicamente está sentado, a veces aportando ideas, pero que, a pesar de todo lo que gana, no aporta algún beneficio a esta sociedad en decadencia? Lastimosamente es así, crecemos con la mentalidad de ser profesores, docentes, maestros, pero la ineficiencia del estado en todo campo (armado, político, económico) ha generado educadores sin motivación, sin profesionalismo y más que todo, sin méritos de transformar a esta sociedad, que poco a poco va cuesta abajo. 
Nos es increíble pensar que alguien podría transformar la sociedad, tal vez nos faltan mejores dirigentes en el gobierno, ya sean de izquierda, o aquellos que no estén a la mano de Uribe, pero realmente no es así; Nosotros como futuros licenciados tenemos la oportunidad, la masa en las manos, de hacer surgir gente de bien, de cambiar la mentalidad de muchos niños y jóvenes que ahora mismo están pensando en no seguir estudiando, evidenciado una Colombia sin oportunidades. Partamos de la experiencia, de recordar cómo eran nuestros profesores cuando niños, algunos sin transmisión de ganas o en otras palabras de cansancio, desmotivación, insuficiencia de autoestima debido a una labor sin incentivos y $\sin$ reconocimiento de la cual ejercen a la gran cantidad de educandos, la cual es participe del aprendizaje dado por esta profesión. Esto solo es una pequeña parte de la desconsideración de la rama nacional del gobierno.

Ahora, indaguemos más a fondo cual sería el maestro cien, o en otras palabras aquella persona que necesita Colombia para un exhortante cambio. El país necesita un maestro que tenga confianza en sí mismo, que lea, escriba, investigue, sueñe y sea comunicativo, que no sea transmisor únicamente de conocimientos sino generador de cambio, que sea creativo, innovador, y tenga sensibilidad para descubrir las aptitudes y actitudes de sus alumnos, que arme a sus pupilos con las herramientas que requieren para generar un cambio fundamental en su propia vida, dicho lo anterior, el maestro actual, tiene la sensibilidad y los sentidos reprimidos, no vibra, no gusta, no oye, no convive y vive con sus alumnos porque solo está pensando en cómo desenvolver los contenidos, además, no tiene el razonamiento lógico y crítico con lo que se ha formado y porque la sociedad lo presiona para que cumpla horarios o todo lo establecido en sus contenidos, igualmente no es coherente con la moral y ética transmitida y exigida a sus alumnos.

Por todo esto, los colegios son sencillamente lugares donde lo único que se hace es charlar acerca de la vida de otros, sitios en los que, lo único que la mayoría de los maestros, docentes y/o profesores hacen, es transmitir conocimientos, pero no los crean, la triste y decepcionante realidad de los colegios hoy en día; a esto debemos agregarle que, hay una relación entre la comunidad educativa y la sociedad en cuanto a la gran masa de jóvenes y niños que no tienen interés por aprender. La sociedad actual y representantes de la educación están en el pasado, mientras que, los más jóvenes están 
en el futuro, por ello es una necesidad fundamental poner acorde el aprendizaje en el colegio con la sociedad moderna, ya sea basándose en una didáctica digital y de igual manera el maestro debe ser un objeto de aprendizaje y de enseñanza moral y ética, igualmente de los dispositivos que nos rodean y que en la población son dependientes hoy en día.

\section{ABOUT THE AUTHOR}

Julián Andrés Alarcón González is currently studying in the new Modern Languages with an emphasis in English program at the Universidad Pedagógica y Tecnológica de Colombia. 